\title{
Magnetic Field Effects on Crystallization of Iron-Based Amorphous Alloys
}

\author{
Reisho Onodera ${ }^{1, *}$, Shojiro Kimura ${ }^{1}$, Kazuo Watanabe ${ }^{1}$, Sangmin Lee $^{2}$, \\ Yoshihiko Yokoyama ${ }^{2}$, Akihiro Makino ${ }^{2}$ and Keiichi Koyama ${ }^{3}$ \\ ${ }^{1}$ High Field Laboratory for Superconducting Materials, Institute for Materials Research, Tohoku University, Sendai 980-8577, Japan
${ }^{2}$ Advanced Research Center of Metallic Glasses, Institute for Materials Research, Tohoku University, Sendai 980-8577, Japan
${ }^{3}$ Graduate School of Science and Engineering, Kagoshima University, Kagoshima 890-0065, Japan
}

\begin{abstract}
The crystallization behavior of iron-based amorphous alloys has been investigated in high magnetic fields by differential thermal analysis (DTA) and magnetization measurements. DTA of Fe-Si-B amorphous alloys showed that the exothermic peaks shift toward higher temperature under high magnetic fields. At $10 \mathrm{~T}$, peak temperatures of the crystallizations increased approximately $3 \mathrm{~K}$, compared with those at a zero magnetic field. Such a variation in the crystallization peak was not observed in the Fe-B-Nb-Y bulk metallic glass (BMG). In the temperature dependence of the saturation magnetization for the Fe-Si-B amorphous alloy, the sudden increase of the magnetization was found at the crystallization temperatures. The magnetization of Fe-Si-B increased 56 and $40 \mathrm{Am}^{2} \mathrm{~kg}^{-1}$ at the first and second crystallization temperatures, respectively. This magnetization behavior indicates the magnetic transition from the paramagnetic to the ferromagnetic state, accompanying the crystallization, whereas there is only a slight increase in magnetization at the crystallization temperature in Fe-B-Nb-Y BMG. The effect of magnetic field on the crystallization peak as observed from DTA is related to the increase in the magnetization at the crystallization temperature. [doi:10.2320/matertrans.M2012242]
\end{abstract}

(Received July 5, 2012; Accepted November 28, 2012; Published January 11, 2013)

Keywords: amorphous alloy, crystallization, differential thermal analysis, magnetization measurement, high magnetic field

\section{Introduction}

Materials processing using high magnetic fields have been investigated extensively in recent years, owing to developments of cryocooled superconducting magnets. The high magnetic field and high temperature environments can be produced easily by using these magnets combined with an electric furnace. The alignment and/or orientation of the material texture, and the control of the amount precipitated by annealing in high magnetic fields have been examined to improve material properties. Several kinds of magnetic field effects on phase transitions or materials processing have been reported, ${ }^{1,2}$ ) such as a shift toward higher transformation temperature between the ferrite and austenite phases by high magnetic fields ${ }^{3)}$ or an increase in coercivity of a Nd-Fe-B permanent magnet. ${ }^{4)}$ These reports demonstrate that a high magnetic field plays an important role to control material functionality.

Iron-based nanocrystalline alloys with excellent soft magnetic properties ${ }^{5,6)}$ are produced from the crystallization of iron-based amorphous alloys. The control of the crystallization is vital for producing their excellent soft magnetic properties. These properties originate from their fine crystal grain and intergranular amorphous layer. ${ }^{7)}$ A careful treatment is required to control the crystal grain size, which should be less than $20 \mathrm{~nm}$ in nanocrystalline alloys. $\left.{ }^{5,6}\right)$ The control of the crystallization for nanocrystalline alloys is usually carried out by adjusting the chemical composition and annealing conditions. However, the addition of other metallic elements to the basic compositions causes a decrease in magnetic flux density, because of the reduction in iron concentration. Thus, a new method is required for the uniform control of the crystal phase grain size to further improve the magnetic properties of nanocrystalline alloys.

*Graduate Student, Tohoku University
The main crystal phase of the iron-based amorphous alloys is a ferromagnetic crystal such as $\alpha-\mathrm{Fe}, \mathrm{Fe}_{2} \mathrm{~B}, \mathrm{Fe}_{23} \mathrm{~B}_{6}$ and $\mathrm{Fe}_{3} \mathrm{Si}^{8-10)}$ The Curie temperature, $T_{\mathrm{C}}$, of the ferromagnetic amorphous phase is usually lower than its crystallization temperature. Therefore, the crystallization is often accompanied by a change from paramagnetic to the ferromagnetic state. Hence, the crystal phase gains larger Zeeman energy, compared with the amorphous phase by applying magnetic fields. Thus, it is considered that the crystallization of ironbased amorphous alloys is enhanced by applying a magnetic field.

The effect of a magnetic field on the crystallization of amorphous alloys has been investigated recently. Fujii et al. reported on the enhancement in the formation of $\{110\}$ texture in the $\alpha-\mathrm{Fe}(\mathrm{Si})$ phase of the $\mathrm{Fe}-\mathrm{Si}-\mathrm{B}-\mathrm{Nb}-\mathrm{Cu}$ nanocrystalline alloy and an increase in the nucleation rate of $\alpha$-Fe(Si) by annealing in magnetic fields. ${ }^{11)}$ Zhuang et al. advocated that a high magnetic field has a strong influence on the nucleation process owing to the difference in permeability between the crystal and amorphous phases of the Zr-based bulk metallic glass. ${ }^{12)}$ In these reports, the samples were annealed in magnetic fields, and then cooled to room temperature. After the thermal treatment, the samples were studied by X-ray diffraction and transmission electron microscopy imaging. From these measurements, they obtained some information about the crystallized texture of the samples annealed in magnetic fields. However, these methods cannot be used to examine the nature of the crystallization kinetics during annealing. The study of kinetics during annealing is important, because it can provide the significant knowledge for controlling the grain size and for elucidating the origin of the magnetic field effect on the crystallization. Thermal analysis and magnetization measurements are suitable for investigating kinetics of the crystallization. These measurements enable us to observe the kinetics in-situ through exothermic or magnetization behaviors 
accompanying the crystallization at high temperature in high magnetic fields.

It is well known that $\mathrm{Fe}-\mathrm{Si}-\mathrm{B}$ and $\mathrm{Fe}-\mathrm{B}-\mathrm{Nb}$ systems have a fundamental composition of iron-based amorphous alloys and have been studied extensively. $\mathrm{Fe}-\mathrm{B}-\mathrm{Nb}-\mathrm{Y}$ is one of $\mathrm{Fe}-$ $\mathrm{B}-\mathrm{Nb}$ compounds, where a few percent yttrium has been added to the basic system. A bulk sample of this compound can be prepared because of its better glass-forming ability, compared with basal composition $\mathrm{Fe}-\mathrm{B}-\mathrm{Nb}$. On the other hand, $\mathrm{Fe}-\mathrm{Si}-\mathrm{B}$ is the basic composition of nanocrystalline alloys such as $\mathrm{Fe}-\mathrm{Si}-\mathrm{B}-\mathrm{Nb}-\mathrm{Cu}$. The investigation of their crystallization in a magnetic field will contribute greatly to the development of the materials processing of nanocrystalline alloys in magnetic fields. Basic information on the crystallization kinetics such as crystallization temperature or activation energy in high magnetic fields, however, has not been reported yet, because no thermal analysis for the amorphous alloys in high magnetic fields has been carried out. In this study, we investigate the crystallization kinetics of the $\left(\mathrm{Fe}_{72} \mathrm{~B}_{24} \mathrm{Nb}_{4}\right)_{95.5} \mathrm{Y}_{4.5}$ bulk metallic glass ( $\mathrm{Fe}-\mathrm{B}-\mathrm{Nb}-\mathrm{Y}$ $\mathrm{BMG}$ ) and the $\mathrm{Fe}_{79} \mathrm{Si}_{12} \mathrm{~B}_{9}$ ( $\left.\mathrm{Fe}-\mathrm{Si}-\mathrm{B}\right)$ amorphous alloys in high magnetic fields, using differential thermal analysis (DTA) and magnetization measurements for the first time.

\section{Experimental Procedure}

The $\mathrm{Fe}-\mathrm{B}-\mathrm{Nb}-\mathrm{Y}$ BMG rod and the $\mathrm{Fe}-\mathrm{Si}-\mathrm{B}$ amorphous ribbon were prepared by the copper mold casting and singlerole melt-spinning, respectively. DTA measurements were carried out in a temperature range of $300-1100 \mathrm{~K}$ in magnetic fields up to $18 \mathrm{~T}$, utilizing an apparatus developed in High Field Laboratory for Superconducting Materials at the Institute for Materials Research of Tohoku University. ${ }^{13)}$ The sample and the reference material temperatures were measured using sheathed $\mathrm{Pt}-13 \% \mathrm{Rh}$ thermocouples. The sample and the reference material were wrapped using aluminum or platinum foils, and were then wrapped around the thermocouple tip. DTA heating rates were $5-20 \mathrm{~K} / \mathrm{min}$. The reference material was $\mathrm{Al}_{2} \mathrm{O}_{3}$. For measurements of $\mathrm{Fe}-\mathrm{Si}-\mathrm{B}$, the sample ribbon and the reference material were wrapped in aluminum foil. On the other hand, for measurements of $\mathrm{Fe}-\mathrm{B}-\mathrm{Nb}-\mathrm{Y}$ BMG, the sample was ground in a tungsten carbide mortar to form a powder from the bulk sample, and the sample powder and the reference material were wrapped in platinum instead of aluminum foils, because the crystallization temperature of $\mathrm{Fe}-\mathrm{B}-\mathrm{Nb}-\mathrm{Y}$ BMG was higher than the aluminum melting temperature.

The temperature dependence of the saturation magnetization was measured by a vibrating sample magnetometer from 300 to $1000 \mathrm{~K}$ at $0.5 \mathrm{~T}$ with a heating rate of $5 \mathrm{~K} / \mathrm{min}$. For each measurement, the sample space was evacuated to less than $10 \mathrm{~Pa}$ by a rotary pump. The temperature accuracy of the experimental data was within $1 \mathrm{~K}$ for each measurement.

\section{Results and Discussion}

\section{1 $\mathrm{Fe}-\mathrm{B}-\mathrm{Nb}-\mathrm{Y}$}

Figure 1 shows the DTA curves of the $\mathrm{Fe}-\mathrm{B}-\mathrm{Nb}-\mathrm{Y}$ BMG powder at 0 and $18 \mathrm{~T}$. Two exothermic peaks due to the crystallizations were observed. The first peak was caused by

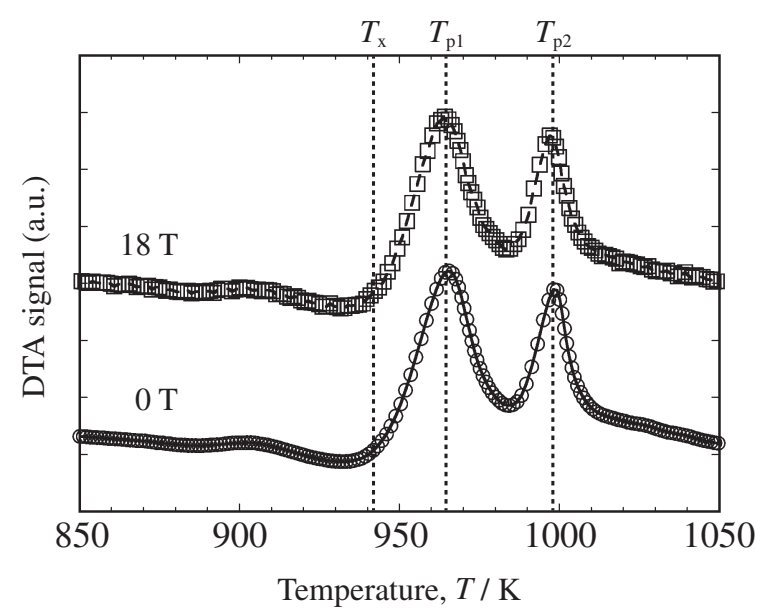

Fig. 1 DTA curves of Fe-B-Nb-Y BMG in a zero field and at $18 \mathrm{~T}$. $T_{\mathrm{x}}$ is the crystallization temperature determined by the onset of the exothermic peak. $T_{\mathrm{p} 1}$ and $T_{\mathrm{p} 2}$ are peak temperatures.

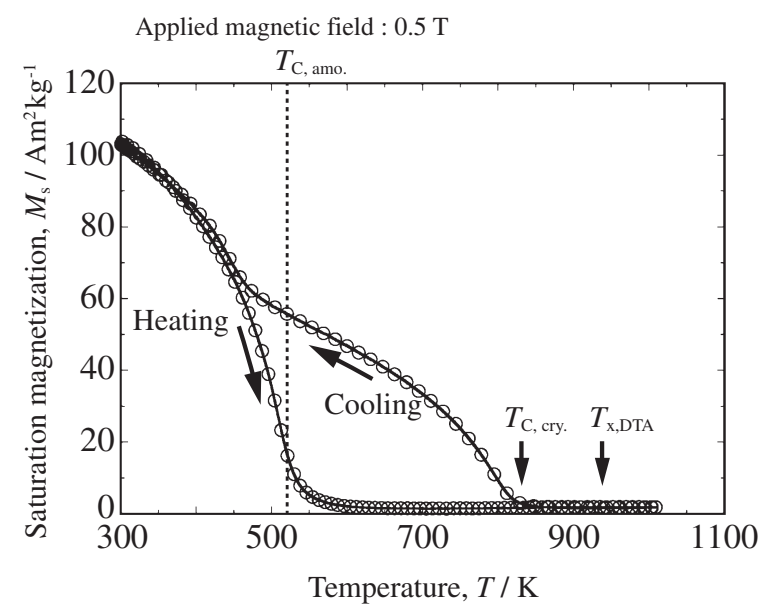

Fig. 2 Temperature dependence of the saturation magnetization of Fe-B$\mathrm{Nb}-\mathrm{Y}$ BMG. $T_{\mathrm{C} \text {,amo. }}$ and $T_{\mathrm{C} \text {,cry. }}$ are Curie temperatures of the amorphous and crystal phase, respectively. $T_{\mathrm{x}}$ is a crystallization temperature determined from DTA.

the crystallization of $\mathrm{Fe}_{23} \mathrm{~B}_{6}$, and the second peak was due to the crystallization of several iron-compounds such as $\mathrm{Fe}_{2} \mathrm{~B}$, $\mathrm{Fe}_{3} \mathrm{~B}$ and FeNbB. $\left.{ }^{9}, 10\right)$ The crystallization temperature, $T_{\mathrm{x}}$, determined by the onset of the crystallization peak, and peak temperatures, $T_{\mathrm{p} 1}$ and $T_{\mathrm{p} 2}$, observed at $18 \mathrm{~T}$, were almost the same as those at a zero magnetic field. Figure 2 shows the temperature dependence of the magnetization of $\mathrm{Fe}-\mathrm{B}-\mathrm{Nb}-\mathrm{Y}$ BMG. The Curie temperature, $T_{\mathrm{C}}$, of the amorphous phase is determined to be $520 \mathrm{~K}$. On the heating process, a change of the saturation magnetization due to the crystallization was scarcely observed at $T_{\mathrm{x}}$. However, the amorphous phase certainly undergoes the crystallization as indicated by exothermic peaks of the DTA curve in this temperature region. Therefore, it is reasonable to consider that the paramagnetic crystal precipitates from the paramagnetic amorphous phase at $T_{\mathrm{x}}$. On the other hand, on the cooling process, the saturation magnetization abruptly increases at $803 \mathrm{~K}$, which is much higher than $T_{\mathrm{C}}$ of the amorphous phase. This behavior suggests that the ferromagnetic order of the crystal phase occurs at this temperature. From the Curie temperature $T_{\mathrm{C}}=803 \mathrm{~K}$, the crystal phase was identified as $\mathrm{Fe}_{3} \mathrm{~B}^{14,15)}$ 

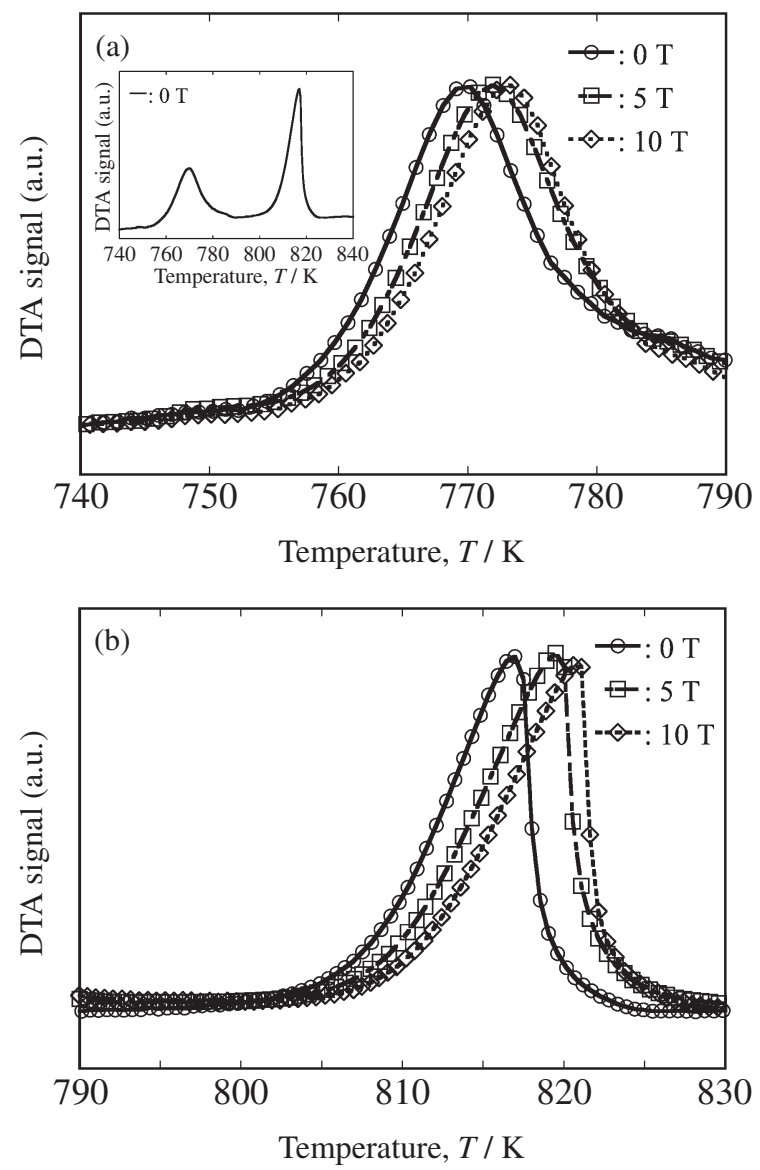

Fig. 3 Magnetic field dependence of (a) first and (b) second crystallization peaks of $\mathrm{Fe}-\mathrm{Si}-\mathrm{B}$ amorphous alloys. Inset shows the DTA curve at $0 \mathrm{~T}$ from 740 to $840 \mathrm{~K}$.

\subsection{Fe-Si-B}

Figures 3(a) and 3(b) show the magnetic field dependence of the first and second crystallization peaks, observed in the Fe-Si-B amorphous ribbon. The inset of Fig. 3(a) shows the DTA curve at $0 \mathrm{~T}$ from 740 to $850 \mathrm{~K}$. The DTA curves in Figs. 3(a) and 3(b) were picked up from the same DTA curves in each magnetic field. The position of DTA curves at 5 and $10 \mathrm{~T}$ in each figure is adjusted, so that the base lines below the onset temperatures of crystallization peaks coincide to those at $0 \mathrm{~T}$, respectively. $\alpha$-Fe and $\mathrm{Fe}_{2} \mathrm{~B}$ crystallize at the first and second crystallizations, respectively. $\mathrm{Fe}-\mathrm{Si}-\mathrm{B}$ behaves differently from $\mathrm{Fe}-\mathrm{B}-\mathrm{Nb}-\mathrm{Y}$ BMG in a magnetic field. The exothermic peaks of $\mathrm{Fe}-\mathrm{Si}-\mathrm{B}$ shift toward higher temperatures in a magnetic field, compared with those at a zero field. The experiment was repeated several times at each magnetic field to confirm data reliability. Table 1 shows average values of the crystallization and peak temperatures at 0,5 and $10 \mathrm{~T}$. We also confirmed similar shifts in crystallization peaks by applying magnetic fields at other heating rates $3,10,15$ and $20 \mathrm{~K} / \mathrm{min}$. The crystallization behavior of the $\mathrm{Fe}-\mathrm{Si}-\mathrm{B}$ amorphous alloy in a magnetic field is clearly different from that of the $\mathrm{Fe}-\mathrm{B}-\mathrm{Nb}-$ Y BMG powder. The observed shifts of crystallization peaks of $\mathrm{Fe}-\mathrm{Si}-\mathrm{B}$ in magnetic fields indicate suppressions in the crystallization from the amorphous phase by a magnetic field.

Figure 4 shows the temperature dependence of the saturation magnetization of the $\mathrm{Fe}-\mathrm{Si}-\mathrm{B}$ amorphous alloy.
Table 1 Crystallization $\left(T_{\mathrm{x} 1}, T_{\mathrm{x} 2}\right)$ and peak $\left(T_{\mathrm{p} 1}, T_{\mathrm{p} 2}\right)$ temperatures of Fe$\mathrm{Si}-\mathrm{B}$ amorphous alloys in zero and high magnetic fields.

\begin{tabular}{|c|c|c|c|c|}
\hline $\begin{array}{c}\text { Magnetic } \\
\text { field, } \\
B / \mathrm{T}\end{array}$ & $\begin{array}{c}1 \mathrm{st} \\
\text { crystallization } \\
\text { temperature, } T_{\mathrm{x} 1} \\
/ \mathrm{K}\end{array}$ & $\begin{array}{c}\text { 1st peak } \\
\text { temperature, } T_{\mathrm{p} 1} \\
/ \mathrm{K}\end{array}$ & $\begin{array}{c}\text { 2nd } \\
\text { crystallization } \\
\text { temperature, } T_{\mathrm{x} 2} \\
/ \mathrm{K}\end{array}$ & $\begin{array}{l}\text { 2nd peak } \\
\text { temperature, } T_{\mathrm{p} 2} \\
/ \mathrm{K}\end{array}$ \\
\hline \multirow{3}{*}{0} & 757.6 & 770.0 & 807.4 & 818.1 \\
\hline & 758.7 & 770.2 & 807.7 & 818.1 \\
\hline & 757.8 & 769.8 & 807.7 & 817.3 \\
\hline Average & 758.0 & 770.0 & 807.6 & 817.8 \\
\hline \multirow{4}{*}{5} & 758.7 & 771.8 & 809.3 & 820.3 \\
\hline & 759.1 & 771.6 & 809.2 & 819.8 \\
\hline & 759.8 & 771.8 & 809.1 & 820.2 \\
\hline & 759.8 & 772.2 & 809.1 & 820.6 \\
\hline Average & 759.4 & 771.9 & 809.2 & 820.2 \\
\hline \multirow{2}{*}{10} & 760.4 & 772.9 & 810.2 & 821.2 \\
\hline & 760.4 & 773.1 & 810.4 & 821.4 \\
\hline Average & 760.4 & 773.0 & 810.3 & 821.3 \\
\hline
\end{tabular}

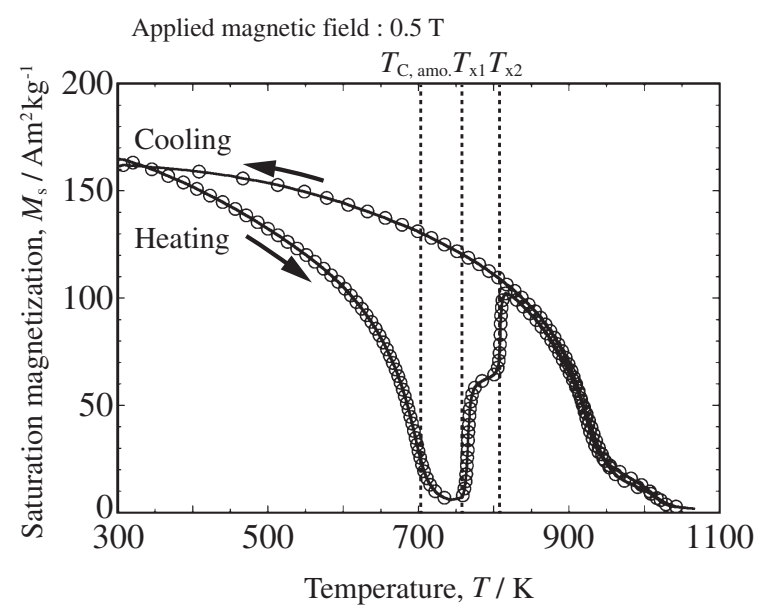

Fig. 4 Temperature dependence of the saturation magnetization of the $\mathrm{Fe}-$ $\mathrm{Si}-\mathrm{B}$ amorphous alloy. $T_{\mathrm{C} \text {,amo. }}$ is Curie temperature of the amorphous phase. $T_{\mathrm{x} 1}$ and $T_{\mathrm{x} 2}$ are crystallization temperatures determined from DTA.

From this result, the Curie temperature of the amorphous phase was determined to be $706 \mathrm{~K}$. Upon heating, the saturation magnetization increases abruptly in two steps at temperatures higher than $706 \mathrm{~K}$. The temperatures at which the steps appear coincide with the crystallization temperatures obtained from our DTA measurements. According to the report by Takahara et al., the product originating from the first and second crystallizations is $\alpha-\mathrm{Fe}$ and $\mathrm{Fe}_{2} \mathrm{~B}$ that contains silicon, respectively. ${ }^{8)}$ The Curie temperatures of pure $\alpha$-Fe and $\mathrm{Fe}_{2} \mathrm{~B}$ are 1043 and $1015 \mathrm{~K}$, respectively. Thus, the increase in the saturation magnetization is caused by the crystallization of ferromagnetic $\alpha$-Fe and $\mathrm{Fe}_{2} \mathrm{~B}$ from the paramagnetic amorphous phase. From the above measurements, it was revealed that the $\mathrm{Fe}-\mathrm{B}-\mathrm{Nb}-\mathrm{Y}$ BMG crystal phase at the crystallization temperature is paramagnetic whereas that of $\mathrm{Fe}-\mathrm{Si}-\mathrm{B}$ is ferromagnetic.

\subsection{Crystallization kinetics in a magnetic field}

Our experiments revealed that crystallization peaks obtained by DTA for the $\mathrm{Fe}-\mathrm{B}-\mathrm{Nb}-\mathrm{Y}$ BMG in a magnetic 
field show no variation, compared with those at a zero magnetic field. However, the shifts of the crystallization peaks toward higher temperatures by applying a magnetic field were observed in the $\mathrm{Fe}-\mathrm{Si}-\mathrm{B}$ amorphous alloy. Differences in the crystallization peak behavior in high magnetic fields between the $\mathrm{Fe}-\mathrm{B}-\mathrm{Nb}-\mathrm{Y}$ BMG and $\mathrm{Fe}-\mathrm{Si}-\mathrm{B}$ amorphous alloys were related to the magnetism of the crystal phase in a high temperature region above the crystallization temperature of these materials. The amorphous phases are paramagnetic at crystallization temperatures in both materials, whereas a clear difference in the magnetism of crystal phases was observed between the $\mathrm{Fe}-\mathrm{B}-\mathrm{Nb}-\mathrm{Y}$ $\mathrm{BMG}$ and $\mathrm{Fe}-\mathrm{Si}-\mathrm{B}$ amorphous alloys. The crystallization temperatures of the $\mathrm{Fe}-\mathrm{Si}-\mathrm{B}$ amorphous alloy, at which the ferromagnetic crystal phase appears, are influenced mainly by high magnetic fields, whereas the crystallization temperature of $\mathrm{Fe}-\mathrm{B}-\mathrm{Nb}-\mathrm{Y}$ BMG, at which the paramagnetic crystal phase appears, remains unchanged by applying magnetic fields.

From the viewpoint of free energy, the ferromagnetic crystal phase gains large Zeeman energy, compared with the paramagnetic amorphous phase by applying a magnetic field. Thus, one may expect the acceleration in the crystallization with ferromagnetic moment in the magnetic field. In fact, Fujii et al. proposed an enhancement in nucleation of the ferromagnetic crystal in a magnetic field, ${ }^{11)}$ by taking into account the contribution of the magnetic energy to the free energy for generating a critical nucleus. This discussion for the magnetic field effect for the crystallization of the amorphous alloys seems not to agree with the DTA measurements for the Fe-Si-B amorphous alloy. However, previous research did not take into account the crystal growth process, which involves the atomic diffusion and interfacial reaction. The effect of a magnetic field on the crystal growth process, especially on atomic diffusion, may be responsible for suppression of the crystallization observed in the Fe-Si-B amorphous alloy. In fact, the diffusion processes in several materials such as carbon in $\gamma$-Fe that is affected by magnetic fields have been reported on Refs. 16-18). Moreover, a previous calculation by Liu et al. ${ }^{19)}$ exhibited that the selfdiffusion coefficient of $\alpha$-Fe decreases in high magnetic fields.

\section{Conclusion}

DTA and magnetization measurements were carried out for the $\mathrm{Fe}-\mathrm{B}-\mathrm{Nb}-\mathrm{Y}$ BMG and $\mathrm{Fe}-\mathrm{Si}-\mathrm{B}$ amorphous alloys in high magnetic fields. DTA of $\mathrm{Fe}-\mathrm{B}-\mathrm{Nb}-\mathrm{Y}$ BMG showed no change in crystallization peaks in magnetic fields up to $18 \mathrm{~T}$. From magnetization measurements, the crystal phase for $\mathrm{Fe}-\mathrm{B}-\mathrm{Nb}-\mathrm{Y}$ BMG showed the paramagnetic behavior. Results from the $\mathrm{Fe}-\mathrm{Si}-\mathrm{B}$ amorphous alloy, in which the ferromagnetic crystal phases appear at crystallization temperatures, showed a shift in the crystallization peak toward higher temperature by applying magnetic fields. This phenomenon indicated the suppression in the crystallization in a magnetic field for $\mathrm{Fe}-\mathrm{Si}-\mathrm{B}$. Thus, the shifts in crystallization peaks are closely related to the crystal phase magnetism in a temperature region higher than the crystallization temperature. To clarify the origin of the crystallization suppression in a magnetic field, it is necessary to take into account the field effect not only on the nucleation but also on the crystal growth of the iron-based amorphous alloys.

\section{REFERENCES}

1) S. Awaji, Y. Ma, W. P. Chen, H. Maeda, K. Watanabe and M. Motokawa: Curr. Appl. Phys. 3 (2003) 391-395.

2) K. Koyama, Y. Mitsui, E. S. Choi, Y. Ikehara, E. C. Palm and K. Watanabe: J. Alloy. Compd. 509 (2011) L78-L80.

3) T. Garcin, S. Rivoirard, C. Elgoyhen and E. Beaugnon: Acta Mater. 58 (2010) 2026-2032.

4) H. Kato, T. Miyazaki, M. Sagawa and K. Koyama: Appl. Phys. Lett. 84 (2004) 4230-4232

5) Y. Yoshizawa, S. Oguma and K. Yamauchi: J. Appl. Phys. 64 (1988) 6044-6046.

6) A. Makino, T. Hatanai, Y. Naitoh, T. Bitoh, A. Inoue and T. Masumoto: IEEE Trans. Magn. 33 (1997) 3793-3798.

7) G. Herzer: Scr. Metall. Mater. 33 (1995) 1741-1756.

8) Y. Takahara and N. Narita: Mater. Trans. JIM 41 (2000) 1077-1081.

9) S. M. Lee, H. Kato, T. Kubota, K. Yubuta, A. Makino and A. Inoue: Mater. Trans. 49 (2008) 506-512.

10) D. H. Kim, J. M. Park and D. H. Kim: J. Mater. Res. 22 (2007) 471477.

11) H. Fujii, V. A. Yardley, T. Matsuzaki and S. Tsurekawa: J. Mater. Sci. 43 (2008) 3837-3847.

12) Y. X. Zhuang, J. Chen, W. J. Liu and J. C. He: J. Alloy. Compd. 504 (2010) S256-S259.

13) S. Awaji, K. Watanabe and M. Motokawa: J. Cryst. Growth 226 (2001) 83-87.

14) C. L. Chien, D. Musser, E. M. Gyorgy, R. C. Sherwood, H. S. Chen, F. E. Luborsky and J. L. Walter: Phys. Rev. B 20 (1979) 283-295.

15) R. Coehoorn, D. B. De Mooij and C. De Waard: J. Magn. Magn. Mater. 80 (1989) 101-104.

16) S. Nakamichi, S. Tsurekawa, Y. Morizono, T. Watanabe, M. Nishida and A. Chiba: J. Mater. Sci. 40 (2005) 3191-3198.

17) S. Fujii and S. Tsurekawa: Phys. Rev. B 83 (2011) 054412-12.

18) S. J. Wang, Y. Wu, X. Zhao and L. Zuo: Mater. Trans. 52 (2011) 139141.

19) X. J. Liu, Y. Lu, Y. M. Fang and C. P. Wang: Calphad 35 (2011) 66-71. 